\title{
Quantitative Risk Assessment of Biogas Plant - Determination of Assumptions and Estimation of Selected Top Event
}

\author{
Petr Trávníček ${ }^{1 *}$, Luboš Kotek², Tomáš Koutný1, Tomáš Vítěz1 \\ 1 Department of Agricultural, Food and Environmental Engineering, Faculty of Agronomy, Mendel University in Brno, \\ Zemědělská 1, 61200 Brno, Czech Republic \\ 2 Department of Production Systems and Virtual Reality, Faculty of Mechanical Engineering, Brno University of Technology, \\ Technická 2896/2, 61669 Brno, Czech Republic \\ * Corresponding author, e-mail: petr.travnicek@mendelu.cz
}

Received: 28 August 2018, Accepted: 29 January 2019, Published online: 10 April 2019

\begin{abstract}
Biogas plants are a specific facility from the QRA (Quantitative Risk Assessment) methodologies' point of view, especially in the case of the determination of the event frequency of accident scenarios for biogas leakage from a gas holder and subsequent initiation. QRA methodologies determine event frequencies for different types of accident events related to vessels made of steel. Gas holders installed at biogas plants are predominantly made of other materials and are often integrated with the fermenter. It is therefore a specific type of gas holder, differing from that which is commonly used in the chemical industry. In addition, long-term experience is not available for the operation of biogas plants, unlike in the chemical industry. The event frequencies listed in the QRA methodologies are not relevant for the risk assessment of biogas plants. This work is focused on setting the prerequisites for QRA of biogas storage, including for example: information on hazardous chemical substances occurring at biogas plants, their classification, and information on the construction of integrated gas holders. For the purpose of the work, a scenario was applied where the greatest damage (to life or property) is expected. This scenario is the leakage of the total volume of hazardous gas substance from the gas holder and subsequent initiation. Based on this information, a "tree" was processed for "Fault Tree Analysis" (FTA), and frequencies were estimated for each event. Thereafter, an "Event Tree Analysis" was carried out. This work follows up on a discussion by experts on the determination of scenario frequencies for biogas plants that was conducted in the past.
\end{abstract}

\section{Keywords}

biogas, leakage, scenarios, Fault Tree Analysis, QRA

\section{Introduction}

Biogas plants are technologies where potentially hazardous substances are produced or stored. The major hazardous substance is biogas with the main hazardous property being its flammability. Under EU Directive No. 2012/18/EU, in Europe most facilities have a below-limit quantity of hazardous substances. Facilities with an over-limit quantity of hazardous substances are the exception. An example is the NAWARO BioEnergie Park in Güstrow, where cogeneration units with a total output of $20 \mathrm{MWel}$ [1] are located. There an excessive amount of hazardous substance (biogas) can be expected. In this case, the biogas consumption with a methane content of $50-55 \% \mathrm{vol}$ is approximately $9600-10000 \mathrm{~m}^{3}$ per hour.

For the purpose of quantitative risk analysis (QRA), it is necessary to have a knowledge of the frequencies of events of accident scenarios. These frequencies of events are possible to determine based on recognized methodologies for QRA in the chemical industry, such as Dutch CPR 18 or methodology by HSE (UK Health and Safety Executive). Unfortunately, these methodologies do not consider construction materials other than steel. However, some important elements of biogas plants are often made from different materials. For example, the gas holder is made from EPDM material.

The research of professional works has shown that discussion on this topic is very limited in professional circles. The work by Heezen et al. [2] is an exception. This work states that the National Institute for Public Health and the Environment (RIVM) has proposed that companies that process safety documentation for a biogas plant falling 
under the SEVESO Directive should consider the fermenter (including the integrated gas holder) as an atmospheric vessel. However, they also state that further research is needed to confirm whether this approach is valid or not.

The frequency of an event is generally determined as the frequency of accidental events divided by the number of operated facilities and their operating times. However, this cannot be used for cases where the frequency is very low, or for cases that have not occurred at all. This is also the case of biogas plant accidents. Two basic approaches can be used to determine the frequency of an event. The first is Probabilistic Risk Analysis using Fault Tree Analysis (FTA) and Event Tree Analysis (ETA). Another method is to use what are called 'precursors' together with Bayesian statistics. However, Bayesian statistics can also be used in Probabilistic Risk Analysis [3]. The following works are worth mentioning, dealing with the possibilities, limitations, advantages and disadvantages of both approaches [4-8, 12].

The purpose of this work is to determine an estimate of frequency of a representative accident scenario at biogas station, which is consistent with QRA methodologies. Representative accident scenario is following: the leakage of the entire volume of substance from the integrated gas holder and subsequent initiation. The paper so follows up on the work by Heezen et al. [2].

\section{Methods}

The Fault Tree Analysis (FTA) method was used to determine the top event frequency estimation. The top event was determined in accordance with the CPR 18 methodology. It is an event in which all hazardous substances have leaked. The available Health and Safety Executive (HSE) databases [9] and specialized work [10] were used to determine the frequency of sub-events representing the tree. The Tecnica Empirica Stima Errori Operatori (TESEO) method was used for Human Reliability Assessment (HRA). The frequency of a representative accident scenario was determined using Event Tree Analysis (ETA).

Some value of the frequency of event was estimated based on information from the authors' accident database. This database records accidents in the timeframe from 2006 to 2017 and contains 241 items. The database contains information about property loss, health damage, locality of accident, causes and consequences of accidents. The database includes accidents in Germany, the Czech Republic, Austria, Lithuania, Switzerland, Great Britain, France, Italy and Luxembourg. Information on accidents originates from public databases, such as ARIA [11], eMARS [12], ZEMA [13], as well as from newspaper articles. The outputs from the database are presented in the authors' work [14].

The probabilities were taken over from the Reference Manual Bevi Risk Assessments [15] for ETA.

\section{Results}

\subsection{Hazardous chemical substances at biogas plants}

The standard procedure for risk analysis, defined by EC Regulation No. 1272/2008, is the determination of hazardous properties and quantities of chemicals stored or processed in the facility.

The type and quantity of chemicals occurring in an object depends on many circumstances, such as the type of biogas plant technology, and the presence of other hazardous substances. These hazardous substances may not be related directly to the operations of a biogas plant, but must be included in the risk analysis. Fertilizers or fuel for agricultural machinery can be included among these substances.

The chemical substances occurring most frequently in a facility in direct connection with the operation of the biogas plant are the following:

- Biogas,

- Engine oil in cogeneration units,

- Refrigerant in refrigeration unit (to reduce biogas moisture),

- Anti-freeze mixture in heating circuits,

- The content of fermenters and tanks for storage of fermentation residues.

Of these substances, only biogas is a hazardous mixture according to Regulation (EC) No 1272/2008. Its hazardous property is primarily flammability or, in the case of a higher concentration of hydrogen sulphide, toxicity.

\subsection{Top event}

The largest quantity of biogas is located in the gas holder. The biogas is located in one or more gas holders, depending on the power of the cogeneration unit. Two gas holders with a volume of approximately $1200 \mathrm{~m}^{3}$ and at overpressure of up to $5 \mathrm{kPa}$ can be presupposed for a total power of $1 \mathrm{MW}$. On the basis of standard CPR 18, several accident events can be assumed. Events may be the following: loss of gas holder integrity and release of biogas into the atmosphere; full bore rupture of a pipe and the release of biogas into the 
atmosphere, etc. The event of the loss of gas holder integrity is selected for the purpose of this paper. This is an event which has the greatest potential to cause damage. The paper is focused on an integrated gas holder, because it is the most common type of biogas holder.

\subsection{Technical solutions of integrated gas holder}

For a better understanding of the function of gas holders, it is advisable to know their design. The most common technical solution of biogas plants is an integrated gas holder, where the gas holder is part of the fermenter. The gas holder is attached to the concrete or steel construction of the fermenter. Membrane mount systems differ, depending on the company supplying the technology.

Fig. 1 shows the attachment detail of a single- layer gas holder, which is made of EPDM membrane. A trapezoidal steel profile is inserted into the reinforced concrete head of the fermenter. Inside this profile, a rubber hose is inserted. The membrane is wound around the rubber hose. The rubber hose is connected to an automatic air pressure plant. During an increase of pressure in the hose, the membrane is pressed against the side wall of the steel profile to create a lock which hermetically separates the biogas in the gas holder from the ambient atmosphere.

This system is particularly advantageous in view of the short time consumed in membrane replacement. In the fermenter, there is a wooden floor on the surface that prevents the membrane from falling into the fermented material. At the same time, the wooden floor offers plenty of space for bacteria- oxidizing hydrogen sulphide.

Fig. 2 shows the attachment system of an integrated gas holder consisting of two membranes. Both membranes are placed over the edge of the reinforced concrete fermenter construction. These membranes are secured by steel plates, which are screwed into the fermenter head around the periphery of the fermenter. Air of a defined pressure is blown into the space between the membranes. The shape of the outer membrane thus remains preserved and does not depend on the amount of stored biogas. The shape of the inner membrane varies according to the gas holder filling level. Support belts are inside the fermenter. Belts prevent the internal membrane from falling into the fermented material.

Fig. 3 shows the last fixing system which is commonly used. It is a single-layer integrated gas holder. The membrane is positioned over the edge of the reinforced concrete construction of the fermenter. The hermetic closure of the gas holder occurs by stretching the membrane by

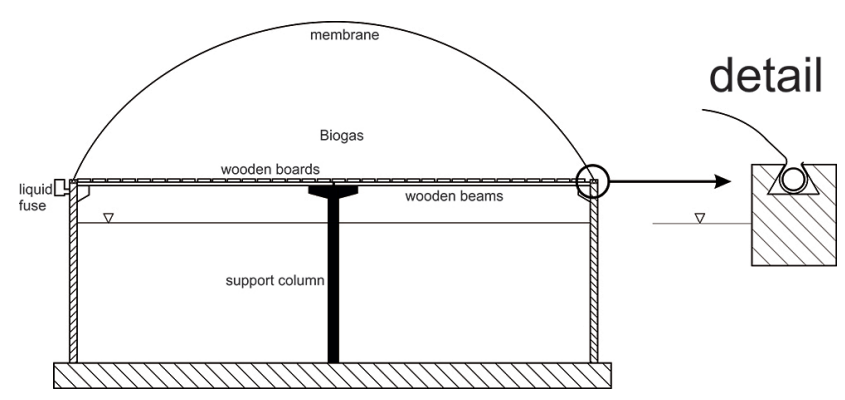

Fig. 1 System A - Attachment detail of an integrated gas holder to the reinforced concrete structure of the fermenter

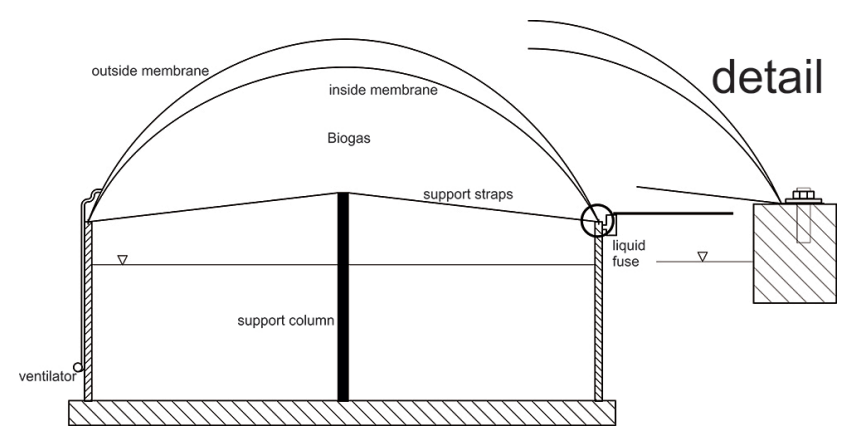

Fig. 2 System B - Attachment detail of an integrated gas holder to the reinforced concrete structure of the fermenter

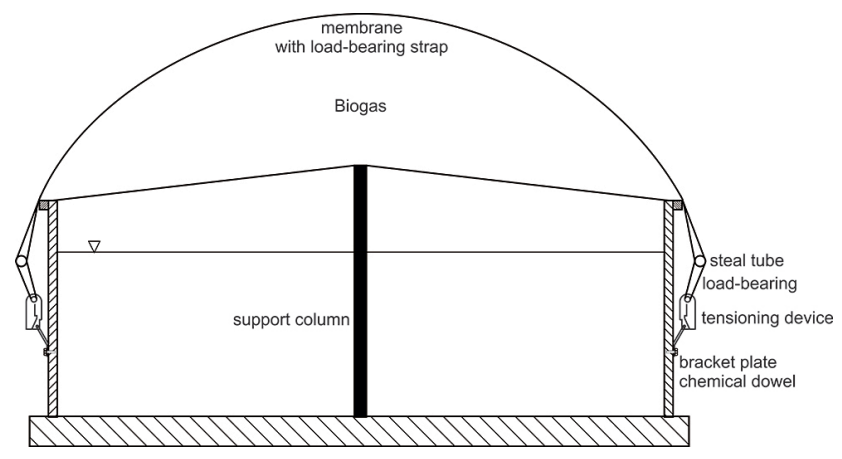

Fig. 3 System C - Attachment detail of an integrated gas holder to the reinforced concrete structure of the fermenter

means of tensioners. As in the previous case, the fall of the membrane into the fermented material is prevented by the support belts within the fermenter.

\subsection{Fault Tree Analysis}

Table 1 lists individual types of events that may result in massive gas leakage from the integrated gas holder. Frequency or probability are assigned to these events. The "tree" is assembled for FTA purposes in Fig. 4. The Fault Tree Analysis method was applied to the fixing system of Type A. This is the most commonly used fixing system in the Czech Republic. The resulting top event frequency is $f=1.6 \times 10^{-2} \mathrm{y}^{-1}$ which is evident from Table 1 . 


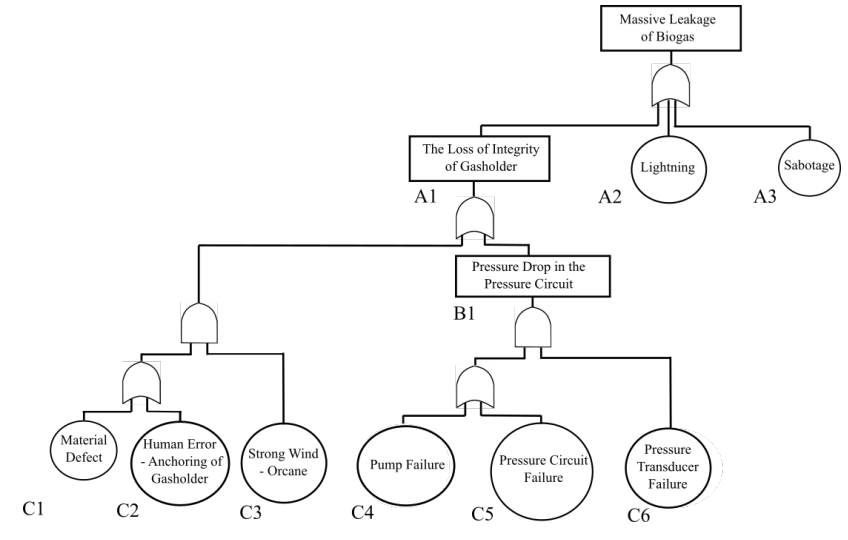

Fig. 4 Fault Tree Analysis for a massive leakage of biogas

Table 1 The estimation of the top event frequency

\begin{tabular}{llccc}
\hline $\begin{array}{l}\text { Event } \\
{\left[\mathrm{y}^{-1}\right]}\end{array}$ & & $\begin{array}{c}\text { Frequency } \\
{[-]}\end{array}$ & Probability & Ref. $^{*}$ \\
\hline $\mathrm{C} 1$ & Material Defect & - & 0.1 & \\
C2 & Human Error & - & $1 \times 10^{-3}$ & \\
C3 & Strong Wind & 0.15 & \\
C4 & Pump Failure & $5 \times 10^{-4}$ & [9] \\
C5 & $\begin{array}{l}\text { Pressure Circuit } \\
\text { Failure }\end{array}$ & $1.6 \times 10^{-6}$ & \\
C6 & Pressure & & \\
& Transducer & $4.7 \times 10^{-3}$ & \\
B1 & Failure & & \\
A1 & Thessure Drop & $2.4 \times 10^{-6}$ & \\
A2 & Integrity & Lightning & $1.5 \times 10^{-4}$ & \\
A3 & Sabotage & $1.0 \times 10^{-3}$ & \\
& Top Event & $1.6 \times 10^{-2}$ & \\
& & & \\
\end{tabular}

* Values where the source is not listed have been estimated on the basis of expert work or calculated (see Section 4, Discussion).

\subsection{Determination of a representative accident scenario and its estimation of probability}

The representative accident scenario - a massive leakage of biogas from the gas holder (caused by extreme weather conditions, mechanical damage, lightning impact, etc.) and subsequent initiation - was considered for the purpose of the scenario probability estimation.

Event Tree Analysis (ETA) was used for this purpose. The results for one fermenter are given in Fig. 5.

\section{Discussion}

\subsection{Classification of hazardous substance}

Biogas is only considered to be 'flammable' for the purpose of this work. However, biogas can also be considered as a 'toxic' gas due to the presence of $\mathrm{H}_{2} \mathrm{~S}$.

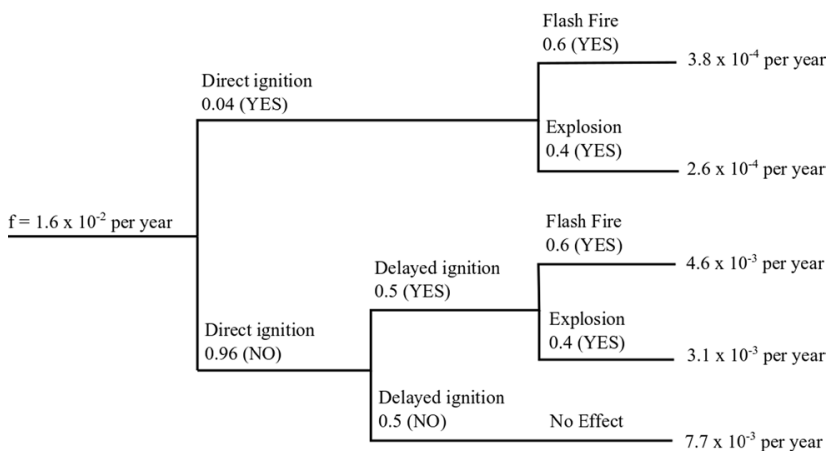

Fig. 5 Event Tree Analysis for massive instantaneous release of biogas

EC Regulation No. 1272/2008, Annex I lists the general limit of $0.1 \%$ by volume for toxic substances in categories $1,2,3$. Heezen et al. [2] explain further interpretations of EC Regulation No. 1272/2008, where biogas with an $\mathrm{H}_{2} \mathrm{~S}$ concentration of less than $2.2 \%(22,000 \mathrm{ppm})$ by volume does not need to be classified as toxic.

High concentrations of $\mathrm{H}_{2} \mathrm{~S}$ in biogas are undesirable in terms of the reliable operation of biogas plant technologies. For that reason, operators are keen to keep $\mathrm{H}_{2} \mathrm{~S}$ values as low as possible. According to other sources, $\mathrm{H}_{2} \mathrm{~S}$ concentrations can vary greatly during anaerobic fermentation. For example, at a biogas plant in the Rhineland, Germany, $\mathrm{H}_{2} \mathrm{~S}$ concentrations fluctuated between 200 ppm and 1000 ppm during the year [16]. Also personal communication with biogas plant operators in the Czech Republic confirmed that their $\mathrm{H}_{2} \mathrm{~S}$ concentration in biogas is below 1000 ppm. However, the $\mathrm{H}_{2} \mathrm{~S}$ concentration in biogas is fundamentally dependent on the composition of the biogas plant feedstock. Our survey shows that biogas produced from a plant biomass, livestock manure and sewage sludge, contains $\mathrm{H}_{2} \mathrm{~S}$ in the range of $0.01-0.08 \%$ (100-800 ppm) by volume. By contrast, biogas produced from waste from the food and paper industries can reach significantly higher $\mathrm{H}_{2} \mathrm{~S}$ concentrations, 0.6-1.5\% (6000$15000 \mathrm{ppm})$. Nevertheless, the number of these facilities are in the significant minority. In connection with toxicity, the escaping gas cannot be underestimated. Some expert publications state that $\mathrm{H}_{2} \mathrm{~S}$ concentrations of 1 000-2 000 ppm or higher, can cause the collapse of the organism to occur in seconds. At these concentrations, respiratory centres fail and there is respiratory arrest. There is the possible risk of mortality within a few minutes [17].

In terms of EC Regulation No. 1272/2008, in most cases, the only hazardous property of biogas is 'flammability'. 


\subsection{The determination of event frequency according to recognised methods for the chemical industry}

The Dutch CPR 18 [18] method and British HSE [9] are recognised methods for quantitative risk assessment. These methods are among the most commonly used methods for quantitative risk assessment in the chemical industry in Europe. However, some problems appear in the quantitative risk assessment of similar technology, such as biogas plants.

The recognised Dutch CPR 18 method sets accident events and their frequencies in general for atmospheric and pressure vessels (including pressure vessels, process vessels, and reactors). However, these are made of steel. The frequency of events reported by the British HSE [9] applies to atmospheric vessels, refrigerated vessels, pressure vessels and chemical reactors. The question is whether biogas holders are considered as atmospheric, pressurised vessels, or as reactors.

We will consider the most commonly installed type of gas holder in biogas plants. This is the integrated gas holder with a maximum overpressure of $5 \mathrm{kPa}$. The limit of overpressure when a vessel is considered as pressurised differs in different regulations. For example, OSHA defines the atmospheric tank as a storage tank that has been designed to operate at atmospheric pressure through $0.5 \mathrm{psig}(11.5 \mathrm{kPa}$ gauge) [19]. According to the American Institute of Chemical Engineers, the atmospheric storage tank as a storage tank is designed to operate at any pressure between ambient pressure and 0.5 psig (11.5 kPa gauge) [20]. European Parliament Directive 2014/68/ EU focuses on pressure vessels with overpressure exceeding 0.5 bar $(50 \mathrm{kPa})$. It also states that: "pressure equipment exposed to a pressure not exceeding 0.5 bar does not pose a significant risk from pressure" [21]. The American Society of Mechanical Engineers (ASME) states the overpressure limit of $15 \mathrm{psig}(100 \mathrm{kPa})$. The Czech Technical Standard ČSN 69 0010-2-1 lists the limit $70 \mathrm{kPa}$ for pressure vessels. Below this limit value, vessels are classified as atmospheric. According to the above data, it is clear that values vary considerably among individual countries and industrial sectors.

Heezen et al. [2] propose fermenters to be considered as atmospheric vessels. Furthermore, the CPR 18 methodology defines process vessels and reactors. Methodology CPR18 states: "In a process vessel, a change in the physical properties of the substance occurs, e.g. temperature or phase. Examples of process vessels are distillation columns, condensers and filters. Vessels where only the level of liquid changes can be considered as pressure vessels." [18]. If we consider the integrated gas holder and the fermenter as a whole, the gas holder could also be defined as a process vessel or reactor. The usage of existing methodologies is questionable for determining the frequency of events for individual accident events.

\subsection{Fault Tree Analysis}

The top event frequency is $f=1.6 \times 10^{-2}$. From the Table 1 , it is evident that events $\mathrm{C} 1, \mathrm{C} 2$ and $\mathrm{C} 3$ play the dominant role in the calculation of top event frequency. Therefore, it can be deduced that other fixing systems have similar values of top event frequencies. The procedure for the determination of event frequency values is as follows.

Level $\mathrm{C} 1$ represents the release of the membrane due to a defect of the material (in conjunction with a strong wind). As noted above, the gas holder membranes are made of rubber-based materials (EPDM). Sufficient data have not been found to determine the event frequency of membrane loss integrity due to strong wind. These are often hidden defects, which occur only after the material has been exposed to higher pressures from wind gusts. The usage of this material (from which the integrated gas holder is made) is non-standard in the chemical industry. Over time, the physical properties of used materials also change as they age. Changes in individual properties depend on many factors, such as the intensity of sunlight, temperature, or rain acidity [22]. The results of tests for changes in the physical properties of EPDM materials used for roof applications are evident in some papers [22-25]. Paper [25] states that the loss of membrane tightness at $25^{\circ} \mathrm{C}$ results after about 87 years of operation. However, the gas holder is exposed to higher temperatures during operation. This temperature can exceed $50^{\circ} \mathrm{C}$ under Central European conditions. The membrane is exposed to low-cycle stress as well. Changing atmospheric conditions (wind, rain, frost) also have a significant influence on material properties. All these factors can cause the reduction of material lifetime. The stiffness of rubber is the next important property which is influenced by temperature. The stiffness of rubber increases with an increase in temperature. The authors in paper [24] state the results of the compression set of EPDM components for a refrigeration system. From the results, it is evident that there is $20 \%$ degradation during 820 hours of material at a temperature of $30^{\circ} \mathrm{C}$.

Based on this information, it is supposed that the loss of membrane integrity results after 40 years of installation operation with a $99 \%$ probability. If it is considered that the lifetime of the material is given by exponential 
distribution, the average lifetime of the material is 8.7 years. On the basis of this distribution, the probability of loss of membrane integrity after 1 year of operation, i.e. $p=0.1$ can be estimated.

A simple TESEO (Tecnica Empirica Stima Errori Operatori) screening method was used for the estimation of the probability of human error at Level C2. This method is commonly used in Human Reliability Assessment (HRA). The following values $\mathrm{K} 1=0.01$, $\mathrm{K} 2=0.1, \mathrm{~K} 3=1, \mathrm{~K} 4=1, \mathrm{~K} 5=1$ were assigned to each factor. The resulting probability value is $p=1 \times 10^{-3}$.

The human error during fixing of the integrated gas holder can related to the rapid gusts of wind. From the authors' database of biogas plant accidents, it is evident that biogas leakage from a gas holder related to strong wind has occurred in the past. There were a total of four cases in 2017 and two cases in 2016, when the membrane was released and biogas leaked into the atmosphere. All events from 2017 occurred in Germany. Two cases occurred in the days when the area was affected by orcans (Thomas, Herwart) and two cases on days when the area was hit by strong wind gusts of up to $125 \mathrm{~km}$ per hour. However, it can be assumed that these extraordinary situations have occurred more times. For example, Santella et al. [26] state that hurricanes in the US territory cause an average of 5.6 leaks of different ranges of hazardous chemicals per 100 facilities (hurricanes of category 1-2 according to the Safir-Simpson scale); in the case of category 3 hurricanes, it is 18.2 leaks per 100 facilities. In addition, the author Moreno [27], without further details, reported that during the period 1995-2014, there were 66 events (whereas the authors' database has a total of 19 events of this type) when biogas from biogas technology leaked into the atmosphere. Some of these were probably influenced by high-speed winds. Between 2007 and 2017, the territory of Central and Western Europe was affected by a total of 16 hurricanes, thus with wind gusts with the potential to damage biogas plants. The frequency of hurricanes in this territory is $f=1.45 \mathrm{y}^{-1}$. However, hurricanes do not strike the entire territory at one time. Hurricanes usually affect a limited territory and rather at higher altitudes. For these reasons, an approximately 10 times lower value of frequency is selected, i.e. $f=0.15 \mathrm{y}^{-1}$. This value was also assigned to Level C3. In the future, the number of extraordinary events of this type can be expected to increase.

Event values that are represented by Levels C4 (compressor failure) and C5 (mechanical pressure circuit damage) were taken from the HSE risk assessment methodology [9]. The frequency of failure of the pressure sensor $f$
$=5.4 \times 10^{-7}$ per hour was taken from the literature source [10]. It is conservatively assumed that the pressure sensor is operating continuously throughout the year. In this case, the event frequency C6 is $f=4.7 \times 10^{-3} \mathrm{y}^{-1}$.

The lightning strike frequency with consequential damage was calculated according to the HSE methodology. According to the methodology, the lightning ground flash density in England is 1.0 flash per $\mathrm{km}^{2}$ per year. However, lightning ground flash density may vary considerably in different parts of Europe. For example, the average value for the Czech Republic for the period 2002 - 2008 was approximately 3.7 lightning strikes per $\mathrm{km}^{2}$ per year [28]. For the purpose of the work, a conservative value of 4.0 lightning strikes per $\mathrm{km}^{2}$ per year was used. If we consider the diameter of the integrated gas holder as about $25 \mathrm{~m}$, the total height of the object as $12 \mathrm{~m}$ and the conservative value of location factor as 1 (no other objects in the area), the probability of damage to the protected object by lightning is $p=0.02$, the resulting frequency for one integrated gas holder is $f=1.5 \times 10^{-4} \mathrm{y}^{-1}$. This value was assigned to Level A2. The authors' database shows that in the years 2006 -2017, four cases were recorded where lightning strikes occurred in biogas plants. In all cases, the lightning struck the gas holder. The result was the damaged membrane and subsequent ignition of the biogas.

In the authors' database [14], two cases of extraordinary situations were recorded that were caused by sabotage. In both cases, the valves closing the fermenters were opened, followed by liquid leakage out of the fermenter. The reason for the sabotage is unknown. In general, it may have been dissatisfied employees, poor interpersonal relationships with the owner of the device, or a desire to be famous. It is also often shown that public opinion is against biogas plant operation. The frequency of sabotage is estimated with respect to the above factors.

It should be noted that the gas holder is not the typical target for a saboteur. A heat source with high thermal output is needed for burnout through the membrane [29]. The perpetrator would probably attracts attention by this act, mainly because most of these attacks take place at night. In this situation, it will be easy to track down him. Under these assumptions, it would be easier for perpetrators to open the valves on the fermenters and to empty them. With respect to the above information, the event frequency is estimated as $f=1 \times 10^{-3} \mathrm{y}^{-1}$.

After evaluation of the entire tree in the FTA, it is obvious that the resulting estimated value of the top event frequency is $f=1.6 \times 10^{-2} \mathrm{y}^{-1}$. 
An event that has the potential to cause damage to human life, the environment or to cause material damage is significant for evaluation in terms of risk analysis. From this point of view, it is a question whether the event of "Damage of biogas holder membrane by strong wind" should be included in the FTA. In this case, the mixture of flammable gas would be diluted rapidly due to the strong wind. It can be assumed that a concentration of methane would not be formed in the biogas plant to cause ignition of the mixture. On the other hand, biological processes do not stop after membrane damage by wind. The biogas will continue to form with the possibility of the formation of a flammable mixture. By applying the same procedure to systems $\mathrm{B}$ and $\mathrm{C}$, it is obvious that the event of "Compressor failure" cannot be considered. It is given by a different fixing system of the membrane. This event would be replaced by another event related to fixing system failure. However, this fact will not have too significant an influence on the value of the top event frequency, because top event frequency is significantly influenced by the following events: C1 (Material Defect), C2 (Human Error), C3 (Strong Wind), which is evident from Table 1.

\subsection{The determination of acceptability of a representative scenario}

Event Tree Analysis shows that the resulting frequency of a representative accident scenario is relatively high $f=4.6 \times 10^{-3} \mathrm{y}^{-1}$ (Explosion) and $f=3.1 \times 10^{-3} \mathrm{y}^{-1}$ (Flash Fire). These values are valid for one fermenter. Two fermenters are often located in biogas plants. In this case, the values of the resulting event frequencies are doubled.

Dutch criterion for societal risk [30] is determined by the Eq. (1):

$$
F_{p}=10^{-3} / N^{2}
$$

where $\mathrm{N}$ is the number of fatally injured. In this case, the stated frequencies are not acceptable. However, this finding is incompatible with the experience of and information about past accidents. Fatal injuries are rather rare, which is evident from papers $[10,14]$. In addition, these fatalities were caused, above all, by poisoning. The explanation may be the following:

- Movement of persons in objects of biogas plants is very sparse.

- Physical properties of biogas differ from methane (e.g. explosive limits, ignition energy, etc.).
- The conditions for a biogas explosion are very specific (e.g. closed space).

\section{Conclusion}

The resulting top event frequency $f=1.6 \times 10^{-2} \mathrm{y}^{-1}$ is approximately three orders of magnitude higher than the value given in the CPR 18 methodology for single-layer atmospheric vessels. The event frequencies (listed in this methodology) were established on the basis of a consensus among experts in the chemical technology, industry and the government administration authorities [31]. This methodology is focused, above all, on the chemical industry.

BEVI methodology was used for the determination of representative scenario frequency. The resulting values were high and the frequencies are not acceptable. This finding is incompatible with operational experience and information about past accidents. For QRA purposes, it seems appropriate to choose the value of event frequency lower. However, according to the author's opinion, this value should not be lower than the event frequency value shown in CPR 18 for the single-containment atmospheric tank.

In the case of biogas plants, the total gas leakage from the integrated gas holder will be positively affected by the fact that the membrane will be located a few metres above ground. Furthermore, biogas with an approximate composition of $60 \%_{\text {vol }}$ methane and $40 \%_{\text {vol }}$ carbon dioxide rather behaves as a neutral gas towards the surrounding atmosphere. From this, it can be deduced that there is a lower probability of biogas ignition. The reason is that most of the sources of initiation (car with running engine, cogeneration unit, operator movement, etc.) are located on the ground. For accidents caused by strong wind, it is also possible to expect a rapid dilution of the flammable mixture by ambient air. In the case of windstorms, the risk of deflagration increases, when an event occurs that the air flows partly around the shifted membrane into the internal parts of the gas holder. In this way, an ignition mixture may be formed. The source of ignition may be, for example: the discharge of an electrical charge which can accumulate on different parts of the fermenter construction due to friction.

\section{Acknowledgment}

This work is an output of research and scientific activities of project Z.02.1.01/0.0/0.0/16_026/0008404 "Mechanical production technology and precision engineering" by financial means from the European Structural and Investment Funds. 


\section{References}

[1] Nawaro BioEnergie AG "NAWARO Profile of the Company", [online], Available at: http://nawaro.ag/en/company/profile/ [Accessed: 20 June 2018]

[2] Heezen, P. A. M., Gunnarsdóttir, S., Gooijer, L., Mahesh S. "Hazard Classification of Biogas and Risks of Large Scale Biogas Production", Chemical Engineering Transactions, 31, pp. 37-42, 2013.

https://doi.org/10.3303/CET1331007

[3] Siu, N. O., Dana L. Kelly, D. L. "Bayesian parameter estimation in probabilistic risk assessment", Reliability Engineering and System Safety, 62(1-2), pp. 89-116, 1998.

https://doi.org/10.1016/S0951-8320(97)00159-2

[4] Yang, M., Khan, F. I., Lye, L. "Precursor-based hierarchical Bayesian approach for rare event frequency estimation: A case of oil spill accidents", Process Safety and Environmental Protection 91(5), pp. 333-342, 2013.

https://doi.org/10.1016/j.psep.2012.07.006

[5] James, W. J., Rasmuson, D. M. "The US NRC's accident sequence precursor program: an overview and development of a Bayesian approach to estimate core damage frequency using precursor information", Reliability Engineering and System, 53(2), pp. 205216, 1996.

https://doi.org/10.1016/0951-8320(96)00064-6

[6] Kirchsteiger, C. "Impact of accident precursors on risk estimates from accident databases", Journal of Loss Prevention in the Process Industries, 10(3), pp. 159-167, 1997. https://doi.org/10.1016/S0950-4230(96)00047-2

[7] Nair, S. "Essence of the Accuracy and Acceptability of Failure Rate Data in Risk Assessment", In: Hazards XXII, Liverpool, United Kingdom, 2011, pp. 611-614.

[8] Khakzad, N., Khan, F., Amyotte, P. "Safety analysis in process facilities: Comparison of fault tree and Bayesian network approaches", Reliability Engineering and System Safety, 96(8), pp. 925-932, 2011.

https://doi.org/10.1016/j.ress.2011.03.012

[9] Health and Safety Executive "Failure Rate and Event Data for use within Risk Assessments", [pdf] HSE, Available at: www.hse.gov. uk/landuseplanning/failure-rates.pdf [Accessed: 20 June 2018]

[10] Cadwallader, L. C. "Reliability Estimates for Selected Sensors in Fusion Application", [online] Available at: https://inis.iaea.org/collection/NCLCollectionStore/_Public/28/044/28044377.pdf?origin=publication_detail [Accessed: 20 June 2018]

[11] S. D. and E. French Ministry of Ecology "ARIA Database", [online] Available at: http://www.aria.developpement-durable. gouv.fr/find-accident/?lang $1 / 4$ en [Accessed: 20 June 2018]

[12] European Commission "eMARS - Major Accident Reporting System. European Commission", [online] Available at: https:// emars.jrc.ec.europa.eu/ [Accessed: 20 June 2018].

[13] Umwelt Bundesamt "Central Reporting and Evaluation Office for Major Accidents and Incidents in Process Engineering Facilities", [online] Available at: http://www.infosis.uba.de/index.php/en/ zema/index.html [Accessed: 20 June 2018]
[14] Travníček, P., Kotek, L., Junga, P., Vítěz, T., Drápela, K., Chovanec, J. "Quantitative analyses of biogas plant accidents in Europe", Renewable Energy, 122, pp. 89-97, 2018. https://doi.org/10.1016/j.renene.2018.01.077

[15] National Institute of Public Health and the Environment (RIVM) "Reference Manual Bevi Risk Assessments", Bilthoven, Netherlands, 2009.

[16] Urban, W., Girod, K., Lohmann, H. "Technologien und Kosten der Biogasaufbereitung und Einspeisung in das Erdgasnetz. Ergebnisse der Markterhebung 2007-2008" (Technologies and costs of biogas upgrading and press into the natural gas grid. Results of the 2007-2008 market survey), [pdf] Fraunhofer-Institut für Umwelt-, Sicherheits- und Energietechnik, (in German). Available at: https://www.infothek-biomasse.ch/images//2008_UMSICHT_ Technologien_und_Kosten_der_Biogasaufbereitung_und_ Einspeisung_in_das_Erdgasnetz.pdf [Accessed: 20 June 2018]

[17] Wexler, P. "Encyclopedia of Toxicology", 2nd ed., Academic Press, USA, 2005.

[18] Uijt de Haag, P. A. M., Ale, B. J. N. "Purple Book: Guidelines for Quantitative Risk Assessment", RIVM, Hague, Netherlands, 1999.

[19] United States Department of Labor - Occupational Safety and Health Administration 2013/1910.119/OSHA Process safety management of highly hazardous chemicals.

[20] American Institute of Chemical Engineers "Process Safety Glossary", [online] Available at: https://www.aiche.org/ccps/ resources/glossary/process-safety-glossary/atmospheric-storage-tank [Accessed: 20 June 2018].

[21] European Parliament Directive 2014/68/EU on the harmonisation of the laws of the Member States relating to the making available on the market of pressure equipment.

[22] Gish, B. D., Jablonowski, T. L. "Weathering Tests for EPDM Rubber Sheets for Use in Roofing Application", [online] Available at: http://docserver.nrca.net/pdfs/technical/461.pdf [Accessed: 20 June 2018].

[23] Tria, T., Robertson, R., Gish, B. "EPDM Roof Membranes: Long Term Performance Revisited", [pdf] International Convention \& Trade Show Reno, Nevada, Available at: http://www.epdmroofs. org/attachments/2004_03_epdmrevisited_rci_trial.pdf [Accessed: 20 June 2018]

[24] Woo, C. S., Park, H. S. "Useful lifetime prediction of rubber component", Engineering Failure Analysis, 18(7), pp. 1645-1651, 2011. https://doi.org/10.1016/j.engfailanal.2011.01.003

[25] Jie, L., Xiangbo, L., Likun, X., Tao, H. "Service Lifetime Estimation of EPDM Rubber Based on Accelerated Aging Tests", Journal of Materials Engineering and Performance, 26(4), pp. 1735-1740, 2017. https://oi.org/10.1007/s11665-017-2519-8

[26] Santella, N., Steinberg, L. J., Aguirra, G. A. "Empirical Estimation of the Conditional Probability of Natech Events Within the United States", Risk Analysis, 31(6), pp. 951-968, 2011. https://doi.org/10.1111/j.1539-6924.2010.01561.x

[27] Moreno, V. C., Papasidero, S., Scarponi, G. E., Guglielmi, D., Cozzani, V. "Analysis of accidents in biogas production and upgrading", Renewable Energy, 96, pp. 1127-1134, 2016. https://doi.org/10.1016/j.renene.2015.10.017 
[28] Novák, P., Žejdlík, T., Tolasz, R. "Deset let využívání dat detekce blesků v Českém hydrometeorologickém ústavu" (Ten years of use of lightning detection data at the Czech Hydrometeorological Institute), [pdf] Czech Hydrometeorological Institute, (in Czech). Available at: http://www.cmes.cz/sites/default/files/MZ\%20 2009_6_blesky.pdf [Accessed: 20 June 2018]

[29] Strauch, R., Reinhold, F. "Brandversuch einer EPDM Folie im Einsatz als Gasspeicher" (Fire test of an EPDM in use as gas holder), [pdf] TÜV Süddeutschland, (in German). Available at: https://www.werkfeuerwehrverband-bayern.de/files/Brandschutz Biogasanlagen.pdf [Accessed: 20 June 2018]
[30] Vrijling J. K., van Geldera, P. H. A. J. M., Ouwerkerk, S. J. "Criteria for acceptable risk in the Netherlands", In: Taylor, C., Van Marcke Infrastucture Risk Management Processes: Natural, Accidental, and Deliberate Hazards, pp. 143-157, 2005. https://doi.org/10.1061/9780784408155.ch05

[31] Pasman, H. J. "History of Dutch process equipment failure frequencies and the Purple Book", Journal of Loss Prevention in the Process Industries, 24(3), pp. 208-213, 2011. https://doi.org/10.1016/j.jlp.2010.08.012 